\title{
Incidence and risk factors for acquired colonization and infection due to extended-spectrum beta-lactamase-producing Gram-negative bacilli: a retrospective analysis in three ICUs with low multidrug resistance rate
}

\author{
Nicolas Massart $^{1,2}$ (D) Christophe Camus ${ }^{1,2,3} \cdot$ François Benezit $^{1,2,3} \cdot$ Mikael Moriconi $^{4} \cdot$ Pierre Fillatre $^{5} \cdot$ Yves Le Tulzo $^{1,2,3}$
}

Received: 22 October 2019 / Accepted: 17 December 2019 / Published online: 2 January 2020

(C) Springer-Verlag GmbH Germany, part of Springer Nature 2020

\begin{abstract}
The purpose of this study is to assess risk factors for the acquisition of extended-spectrum $\beta$-lactamase-producing Gram-negative bacilli (ESBL-GNB) colonization and infection (AI) in ICUs with low ESBL-GNB prevalence rate. We conducted a retrospective observational study in three ICUs in Bretagne, France. All patients admitted from January 2016 to September 2017 with a length of stay of 2 days or more were included. Universal screening for ESBL-GNB colonization was performed in all participating ICUs. Of the 3250 included patients, 131 (4.0\%) were colonized at admission, 59 acquired colonization while hospitalized (1.9\%; $95 \%$ CI [1.5-2.5\%]), and $15(0.5 \%$; $95 \%$ CI [0.3-0.8\%]) acquired ESBL-GNB infections. In the case of infection, the specificity and the negative predictive values of preexistent colonization for the ESBL-GNB etiology were 93.2\% [91.5-95.1\%] and 95.2\% [93.5-97.1\%], respectively. Colonization was the main risk factor for ESBL-GNB AI (OR = 9.61; 95\% CI [2.86-32.29]; $p<0.001)$. Antimicrobial susceptibility of non-ESBL-GNB isolates responsible for AI was similar for any non-carbapenem $\beta$-lactam (95\%) and imipenem (94\%). ESBL-GNB AIs were rare in ICUs with low ESBL-GNB prevalence rate. Prior colonization was the main risk factor for subsequent infection. Empirical carbapenem therapy could be avoided in non ESBL-GNB colonized patients with suspected AI.
\end{abstract}

Keywords Extended-spectrum beta-lactamase-producing Enterobacteriaceae - Gram-negative bacteria · Decontamination . Healthcare-associated pneumonia $\cdot$ Bacteremia

Electronic supplementary material The online version of this article (https://doi.org/10.1007/s10096-019-03800-y) contains supplementary material, which is available to authorized users.

Nicolas Massart

nicolasmassart@hotmail.fr

1 Service de Maladie Infectieuse et de Réanimation Médicale CHU de Rennes, 2, rue Henri le Guilloux, 35000 Rennes, France

2 Faculté de Médecine, Biosit, Université Rennes 1, F-35043 Rennes, France

3 Inserm-CIC-1414, Faculté de Médecine, Université Rennes I, IFR 140, F-35033 Rennes, France

4 Service de Réanimation, CH de Quimper, 14bis Avenue Yves Thépot, 29107 Quimper, France

5 Service de Réanimation, CH de St Brieuc, 10, rue Henry le Guilloux, 22000 Saint-Brieuc, France

\section{Introduction}

Critically ill patients in the intensive care unit (ICU) have a high risk of acquired infections (AIs) [1, 2], which increase morbidity and, to some extent, mortality [3]. Pneumonia and bloodstream infections (BSI) are the most common infections with a reported incidence rate of 15 per 1000 ventilator-days [2] and 9.5 per 1000 patient-days [1], respectively. Among multidrug-resistant organisms (MDROs) [4-7], extendedspectrum beta-lactamase-producing Gram-negative bacilli (ESBL-GNB) have an increasing prevalence reaching critical point in some ICUs [7, 8], leading to the unrestricted use of carbapenems in order to avoid inappropriate antimicrobial therapy [8-10].

The challenge of ESBL-GNB has been overemphasized [11] as compared with real life in specific locations. In contrast, risk factors for ESBL-GNB acquired colonization and infection have been unfrequently assessed in ICUs with lower 
prevalence rates [12-15]. The identification of risk factors could help clinicians to target the use of broad-spectrum antibiotics in this setting. The aim of our study was to assess the incidence and risk factors for ESBL-GNB acquired colonization and infection in ICUs with low prevalence of ESBLGNB.

\section{Materials and methods}

\section{Settings and patients}

We conducted a retrospective observational study in three French ICUs. The largest ICU (ICU 1) was a medical unit with 22 acute-care beds in a tertiary care university hospital. Unlike the two other centers, this ICU used multiple-site decontamination in intubated patients. It consists of the administration of topical antibiotics (tobramycin, colistin, and amphotericin B) four times daily in the oropharynx and the gastric tube, chlorhexidine body washing, and nasal mupirocin, in all intubated patients for the period of intubation [16]. The other two units were polyvalent ICUs with 14 beds (ICU 2) and 12 beds (ICU 3). Every ICU followed the recommendations of the French Society for Hospital Hygiene regarding the prevention and treatment of AI (available at https://sf2h.net). Each center had a nosocomial infection committee for the prevention and prospective census of AI.

We screened all admitted patients from January 1, 2016, to September 10,2017. Patients with a length of stay of 2 days or more were included. Because rectal screening for ESBL-GNB colonization and report of AIs are routine care, the institutional ethics committee approved the study and the requirement for written informed consent was waived.

\section{Data collection and definitions}

ESBL-GNB carriage was screened on a rectal swab at admission, every week afterwards and at ICU discharge. Samples were then inoculated onto antibiotic selective agar. The synergy between third generation cephalosporin and clavulanate was confirmed using a double-disk synergy test.

Colonization at admission was defined as a positive first rectal swab for ESBL-GNB performed within $48 \mathrm{~h}$ of admission. Acquisition of colonization was defined as a subsequent positive rectal swab after a negative first swab. Patients with ESBL-GNB AI were considered colonized prior to infection if their screening rectal swab was positive either before or on the day of the microbial diagnosis of infection.

Infection was considered acquired in the ICU when it was diagnosed $48 \mathrm{~h}$ after admission and was not incubating on admission. The diagnosis of pneumonia included both ventilator-associated pneumonia and ICU-acquired pneumonia that developed in non-ventilated patients and was made based on clinical signs (fever), radiological findings (new infiltrate on chest-X-ray or CT scan), and a positive microbiological culture of an endotracheal aspirate $\left(\geq 10^{6}\right.$ colonyforming units $/ \mathrm{mL})$ or a bronchoalveolar lavage $\left(\geq 10^{4}\right.$ colony-forming units $/ \mathrm{mL}$ ). BSI was diagnosed following one or more positive blood culture as defined by the CDC [17].

For the purpose of this study, we estimated the number of days with colonization and the number of days without colonization before the occurrence of ESBL-GNB infection according to the method reported by Frencken et al. [13] Supplementary Fig.1).

Other collected data were age, sex, reason for admission (medical/surgical), Simplified Acute Physiology Score II (SAPS II) at admission, length of stay in ICU, intubation for more than 2 days, admission in ICU 1 versus ICU 2 and 3, and outcome.

\section{Primary and secondary objectives}

The primary objective of the study was to assess the incidence and risk factors of ESBL-GNB acquired colonization and infection. Spectrum of AIs and antimicrobial susceptibility was the secondary objective.

\section{Statistical analysis}

Statistical analysis was performed with the statistical software $\mathrm{R}$ 3. 4. 3. Incidence rate and prevalence were expressed with the 95\% confidence interval (95\% CI), categorical variables as number (percentage), and continuous variables as median and interquartile range (IQR). When appropriate, the chi-square test and the Fisher exact test were used to compare categorical variables. The Man-Whitney $U$ test and the Kruskal-Wallis test were used for continuous variables when applicable. Multivariate logistic regression analysis was used to study risk factors for ESBL-GNB acquired colonization and acquired infection. Variables with a $p$ value $<0.2$ in the univariate analysis or those clinically relevant irrespective of the $p$ value were included for the multivariate analysis. All tests were two-sided, and a $p$ value less than 0.05 was considered statistically significant.

\section{Results}

\section{Study population}

Among 3861 admitted patients, 3250 with an ICU length stay of 2 days or more were all included in the study (Fig. 1). SAPS II was 40 [28-56] and age was 62.1 years [51.0-71.0]. One hundred and thirty-one patients $(4.0 \%)$ were colonized with ESBL-GNB at admission, varying from 2.0 to $4.8 \%$ depending on the ICU (Table 1, Supplementary Table 1). One 
Fig. 1 Study flow chart. ICU intensive care unit, ESBL-GNB extended-spectrum betalactamase-producing Gramnegative bacilli

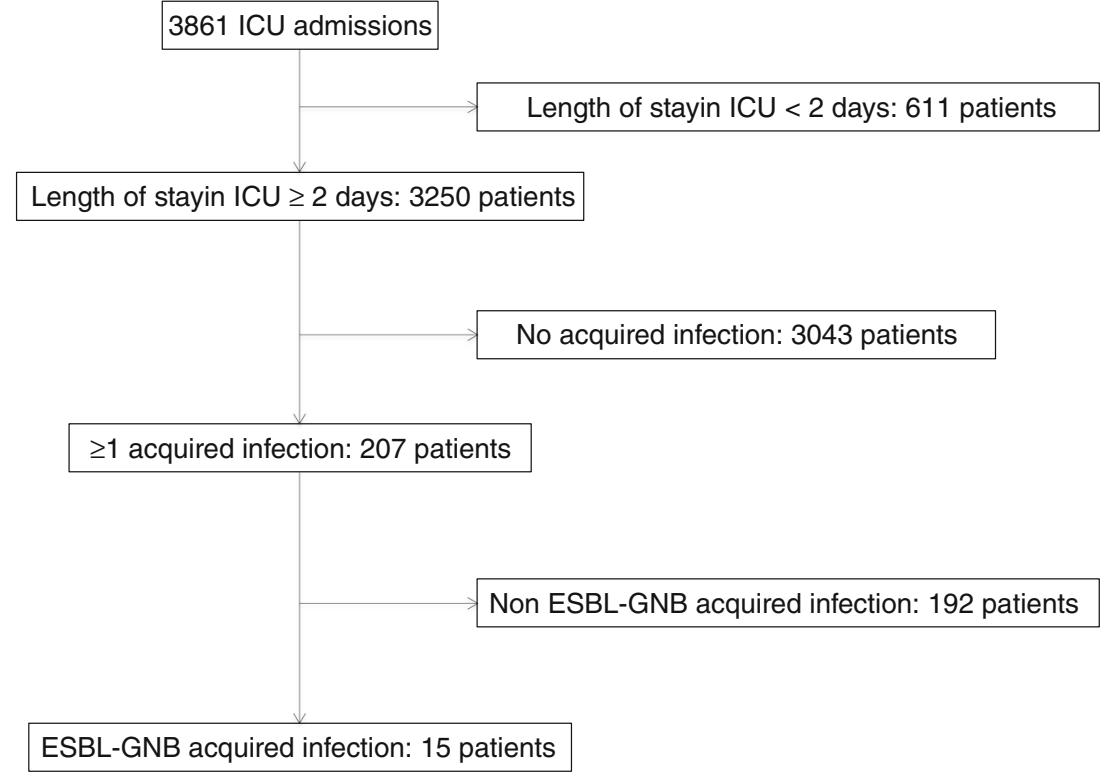

thousand five hundred and seven patients (46.4\%) were intubated for more than $48 \mathrm{~h}$. The average length of stay in ICU was 4 days [3-9] and the overall ICU mortality was $19.8 \%$.

\section{ESBL-GNB acquired colonization}

Among the 3119 patients not colonized at admission, 59 (1.9\%; 95\% CI [1.5-2.5]) acquired ESBL-GNB colonization during their ICU stay with a median length of stay of 7 days [5-14] before colonization acquisition. These patients had a higher SAPS II score than those without acquired ESBL-GNB colonization (48 [34-62] versus 39 [28-55], $p=0.01$ ). Intubation for $48 \mathrm{~h}$ or more $(\mathrm{OR}=6.02$ [2.86-12.68], $p<0.001)$ and admission in ICU $1(\mathrm{OR}=0.39$ [0. 22-0.70], $p=0.002$ ) were independent risk factors for ESBL-GNB acquired colonization (Table 2).

\section{ESBL-GNB acquired infection}

Fifteen infections occurred during a total of 25,857 patientdays at risk, with calculated incidence rates of 0.46 per 100

Table 1 Baseline characteristics and outcome of study patients

\begin{tabular}{|c|c|c|c|c|c|c|}
\hline & $\begin{array}{l}\text { All patients } \\
n=3250\end{array}$ & $\begin{array}{l}\text { Patients never } \\
\text { colonized with } \\
\text { ESBL-GNB } \\
n=3060\end{array}$ & $\begin{array}{l}\text { Patients colonized } \\
\text { with ESBL-GNB } \\
\text { at admission } \\
n=131\end{array}$ & $\begin{array}{l}\text { Patients with } \\
\text { acquired ESBL- } \\
\text { GNB colonization } \\
n=59\end{array}$ & $\begin{array}{l}\text { Patients with } \\
\text { non-ESBL-GNB } \\
\text { acquired infection } \\
n=192\end{array}$ & $\begin{array}{l}\text { Patients with } \\
\text { ESBL-GNB } \\
\text { acquired } \\
\text { infection } n=15\end{array}$ \\
\hline Age, years [IQR] & $62.1[51.0-71.0]$ & $62.0[50.0-70.9]$ & $65.8[56.0-72.0]$ & $66.0[56.3-75.0]$ & $64.8[55.0-71.5]$ & $70.7[64.5-75.5]$ \\
\hline $\begin{array}{l}\text { Simplified Acute Physiology } \\
\text { Score II [IQR] }\end{array}$ & $40[28-56]$ & $39[28-55.0]$ & $46\left[\begin{array}{lll}3 & 3 & -58\end{array}\right]$ & $48[34-62]$ & $51[38-64]$ & $61[46-67]$ \\
\hline \multicolumn{7}{|l|}{$\begin{array}{l}\text { Reason for admission, } \\
\text { no. }(\%)\end{array}$} \\
\hline Surgical & $443(13.6)$ & $412(13.5)$ & $17(13.9)$ & $13(22.0)$ & $33(17.2)$ & $2(13.3)$ \\
\hline Medical & $2445(75.2)$ & $2346(76.6)$ & $105(80.2)$ & $41(69.5)$ & $132(68.8)$ & $13(86.6)$ \\
\hline Not precise & $362(11.1)$ & $302(9.9)$ & $9(6.9)$ & $5(8.5)$ & $27(14.1)$ & - \\
\hline Male, no. (\%) & $2074(63.8)$ & $1936(63.3)$ & $92(70.2)$ & $45(76.3)$ & $144(75.0)$ & $12(80.0)$ \\
\hline $\begin{array}{c}\text { ESBL-GNB colonization } \\
\text { at admission, no. }(\%)\end{array}$ & $131(4.0)$ & 0 & $131(100)$ & - & $3(1.6)$ & $4(26.6)$ \\
\hline $\begin{array}{l}\text { ESBL-GNB acquired } \\
\text { colonization, no. }(\%)\end{array}$ & $59(1.8)$ & - & - & $59(100)$ & $10(5.2)$ & $4(26.7) \S$ \\
\hline $\begin{array}{l}\text { Days after admission, } \\
\text { days }[\mathrm{IQR}]^{*}\end{array}$ & $7[5-14]$ & - & - & $7[5-14]$ & $14[11-25]$ & $10[8-14]$ \\
\hline $\begin{array}{l}\text { ESBL-GNB acquired infection, } \\
\text { no. }(\%)\end{array}$ & $15(0.5)$ & $7(0.2)$ & $4(3.1)$ & $4(6.8) \S$ & - & $15(100)$ \\
\hline Intubation duration $>48 \mathrm{~h}$, no. $(\%)$ & $1507(46.4)$ & 1395 (45.6) & $61(46.6)$ & $51(86.4)$ & $163(84.9)$ & $13(86.6)$ \\
\hline Length of stay in ICU, days [IQR] & $4[3-9]$ & $4[2-8]$ & $5[3-9]$ & $16[9-33]$ & $20[9-35]$ & $25[12-41]$ \\
\hline Death in ICU, no. (\%) & $645(19.8)$ & $596(19.5)$ & $37(28.2)$ & $12(20.3)$ & $63(32.8)$ & $5(33.3)$ \\
\hline
\end{tabular}

$I C U$ intensive care unit $E S B L-G N B$ extended-spectrum beta-lactamase-producing Gram-negative bacilli

*In patients with acquired colonization only 
Table 2 Risk factors for acquired colonization with extended-spectrum $\beta$-lactamase-producing Gram-negative bacilli

\begin{tabular}{|c|c|c|c|c|c|c|}
\hline \multirow[t]{2}{*}{ Variable } & \multicolumn{3}{|c|}{ Univariate } & \multicolumn{3}{|c|}{ Multivariate } \\
\hline & OR & $95 \% \mathrm{CI}$ & $p$ value & OR & $95 \% \mathrm{CI}$ & $p$ value \\
\hline Age $>65$ years & 1.33 & $0.80-2.23$ & 0.27 & & & \\
\hline Simplified Acute Physiology Score II $>40$ & 1.97 & $1.15-3.40$ & 0.014 & 1.31 & $0.71-2.38$ & 0.38 \\
\hline Male & 1.77 & $0.97-3.25$ & 0.06 & 1.47 & $0.79-2.73$ & 0.22 \\
\hline Surgical reason for admission & 1.81 & $0.96-3.40$ & 0.07 & 1.80 & $0.91-3.31$ & 0.09 \\
\hline Intubation duration $>48 \mathrm{~h}$ & 6.62 & 3. $24-13.50$ & $<0.001$ & 4.80 & $2.26-10.24$ & $<0.001$ \\
\hline Admission in ICU 1 & 0.33 & $0.19-0.58$ & $<0.001$ & 0.39 & $0.22-0.70$ & 0.002 \\
\hline
\end{tabular}

OR odds ratio, $95 \%$ CI 95 percent confidence interval

admissions [0.26-0.76] and 0.58 per 1000 patient-days [0.49$0.68]$. Six cases (40\%) had prior ESBL-GNB colonization and 9 had not (Table 3), yielding incidence density rates of 4.73 per 1000 days with colonization and 0.37 per 1000 days without colonization respectively (incidence rate ratio 12.86 [4.08-39.31]; $p<0.001)$. There were 8 pneumonias $(0.3 \%$ $[0.1-0.5 \%])$ and 7 BSIs $(0.2 \%$ [0.1-0.4\%]) (Table 3). The delay to the onset was similar between cases with and cases without prior colonization $(p=0.82)$. Mortality in the ICU was similar between patients with ESBL-GNB AI and those with other AIs (33.3\% versus $32.8 \%, p=0.92$ ).

One hundred and ninety-two patients $(5.9 \%)$ acquired 204 infections (pneumonia 122; BSI 82) not due to ESBL-GNB. Among the 207 patients who acquired any type of infection, 19 had previous ESBL-GNB colonization. In these patients, 6 acquired ESBL-GNB infection (31.6\%), whereas 9 over 188 non-colonized patients (4.8\%) acquired ESBL-GNB infection (relative risk 6.60 [2.23-17.57]). The positive and negative predictive values of ESBL-GNB colonization for ESBL-GNB etiology of AI were $31.6 \%$ [14.5-50.5\%] and 95.2\% [93.5$97.1 \%]$, respectively, whereas sensitivity and specificity were $40.0 \%$ [18.4-64.0\%] and 93.2\% [91.5-95.1\%]. By logistic regression analysis, simultaneous or preexistent ESBL-GNB colonization was the main risk factor for ESBL-GNB AI $(\mathrm{OR}=9.61$ [2.86-32.29], $p<0.001)$ (Table 4).

\section{Prevalence of ESBL-GNB}

Taking into account 131 patients who were colonized at admission, 59 patients who acquired colonization in the ICU, and 7 non-colonized patients who acquired ESBL-GNB infection, the overall prevalence rate of ESBL-GNB in was $6.1 \%$ [5.2-6.9\%] and varied from 4 to $7.5 \%$ between ICUs (Supplementary Table 1).

\section{Micro-organisms identified in acquired infections and antimicrobial susceptibility}

The microorganisms and antimicrobial susceptibility are shown in Table 5. In non-ESBL microorganisms, GNB $(55 \%)$ were the most frequent (Enterobacteriaceae, 32.4\%; Pseudomonas aeruginosa, $17.8 \%$ ). Aerobic GNB were mostly susceptible to all tested antimicrobials, without any major difference between 3rd-generation cephalosporins and imipenem.

All ESBL-GNB responsible for AIs were susceptible to amikacin and imipenem. In 13 of the 15 patients (86.7\%) with ESBL-GNB AI, antimicrobial therapy was considered to be appropriate. Among 129 colonization isolates tested, all were susceptible to amikacin and only 3 (two Pseudomonas aeruginosa and one Klebsiella pneumoniae) were resistant to imipenem (Supplementary Table 2).

Table 3 Characteristics of infection due to extended-spectrum $\beta$-lactamase-producing Gram-negative bacilli acquired infection

\begin{tabular}{llll}
\hline & Total & Previously colonized patients & Non-previously colonized patients \\
\hline Number & 15 & 6 & 9 \\
Delay of onset, days * & $9[2-44]$ & $9[2-22]$ & $3[2-44]$ \\
Pneumonia, no. (\%) & $8(53.3)$ & $3(50.0)$ & $5(55.5)$ \\
Bloodstream infection, no. (\%) & $7(46.6)$ & $3(50.0)$ & $4(44.4)$ \\
Death in ICU, no. (\%) & $5(33.3)$ & $2(33.3)$ & $3(33.3)$ \\
\hline
\end{tabular}

ICU intensive care unit

*Results are expressed with median and [minimal-maximal] 
Table 4 Risk factors for extended-spectrum $\beta$-lactamase-producing Gram-negative bacilli acquired infection in 207 patients with acquired infection

\begin{tabular}{|c|c|c|c|c|c|c|}
\hline \multirow[t]{2}{*}{ Variable } & \multicolumn{3}{|c|}{ Univariate } & \multicolumn{3}{|c|}{ Multivariate } \\
\hline & OR & $95 \% \mathrm{CI}$ & $p$ value & OR & $95 \% \mathrm{CI}$ & $p$ value \\
\hline Age $>65$ years & 2.99 & $0.92-9.72$ & 0.07 & 3.17 & $0.92-10.87$ & 0.07 \\
\hline Simplified Acute Physiology Score II $>40$ & 1.82 & $0.49-6.68$ & 0.90 & & & \\
\hline Male & 1.35 & $0.36-4.96$ & 0.44 & & & \\
\hline Surgical reason for admission & 0.82 & $0.17-3.85$ & 0.80 & & & \\
\hline Intubation duration $>48 \mathrm{~h}$ & 1.16 & $0.25-5.40$ & 0.85 & & & \\
\hline ESBL-GNB colonization & 9.18 & $2.83-29.77$ & $<0.001$ & 9.61 & $2.86-32.29$ & $<0.001$ \\
\hline
\end{tabular}

95\% CI, 95\% confidence interval; ESBL-GNB, extended-spectrum $\beta$-lactamase-producing Gram-negative bacilli

\section{Discussion}

The ESBL-GNB prevalence rate has ranged from $5.7 \%$ to $48.0 \%[7,14,15,18-22]$. In a recent meta-analysis, Detsis et al. [18] reported the rate of ESBL-GNB acquired colonization in 13 studies and the ESBL-GNB prevalence rate could be calculated in 10 . This review suggests that a low prevalence rate is below $10 \%[15,20,21]$, intermediate rate is $10-20 \%$, and high rate is above $20 \%$ [18-20].

The main finding of this study was that very few patients $(0.46 \%)$ acquired ESBL-GNB AIs in ICUs with low prevalence rate of resistance. Prior or simultaneous ESBL-GNB colonization was a strong risk factor for ESBL-GNB AI. This is consistent with other studies with either low [15] or high [19] ESBL-GNB prevalence rate. In patients with suspected or confirmed infection, the relative risk for the ESBL-GNB etiology after prior colonization with ESBLGNB has been diversely assessed depending on local epidemiology. Houard et al. [19] reported a relative risk of $2.6[1.2-5.6]$ in an ICU with ESBL-GNB prevalence rate of $48 \%$. In contrast, Bruyère et al. [15] found a much higher risk (77.5 [23.7-253.4]) in ICUs with a prevalence rate of 7.3\%. In our study, the relative risk was not as high (6.6 [2.2-17.6]). Differences were due to the lower rate of ESBL-GNB AI in non-colonized patients reported by Bruyère $(0.6 \%$ versus $4.8 \%$ in our study), also explaining the higher negative predictive value of prior colonization in this study $(99.5 \%$ versus 95.2\%).

Another important finding in our study was that the majority of ESBL-GNB AIs occurred in non-colonized patients, suggesting an exogenous cause of AI in some cases. ESBLGNB infection in non-colonized patients has been reported previously with various rates. Jalalzaï et al. observed exogenous infection in 2 of 6 ESBL-GNB AIs [14] and Bruyère et al. in 3 among 20 ESBL-GNB AIs [15] while Prevel et al. reported no infection in non-colonized patients during a 6-

Table 5 Microorganisms involved in 219 acquired infections and antimicrobial susceptibility

\begin{tabular}{|c|c|c|c|c|c|c|c|c|}
\hline \multirow[t]{2}{*}{ Microorganisms } & \multirow[b]{2}{*}{$\begin{array}{l}\text { Number of } \\
\text { isolates }\end{array}$} & \multicolumn{7}{|c|}{ Antimicrobials: no. susceptible/no. tested (\%) } \\
\hline & & $\begin{array}{l}\text { Any non-carbapenem } \beta \text { - } \\
\text { lactam }\end{array}$ & Cefepime & Ceftazidime & $\begin{array}{l}\text { Piperacillin- } \\
\text { tazobactam }\end{array}$ & Imipenem & Amikacin & Methicillin \\
\hline \multicolumn{9}{|c|}{ Non-ESBL-producing microorganisms } \\
\hline Enterobacteriaceae & 69 & $52 / 53(98.1)$ & $49 / 50(98.0)$ & $47 / 50(94.0)$ & $44 / 53(83.0)$ & $53 / 55(96.4)$ & $37 / 41(90.2)$ & - \\
\hline Pseudomonas aeruginosa & 38 & $35 / 38(92.1)$ & $34 / 38(89.5)$ & $34 / 38(89.5)$ & $35 / 38(92.1)$ & $35 / 38(92.1)$ & $37 / 38(97.4)$ & - \\
\hline Acinetobacter species & 6 & $5 / 6(83.3)$ & $5 / 6(83.3)$ & $5 / 6(83.3)$ & $5 / 6(83.3)$ & $5 / 6(83.3)$ & $5 / 6(83.3)$ & - \\
\hline Anaerobes & 5 & $4 / 4(100)$ & - & - & $4 / 4(100)$ & - & - & - \\
\hline Staphylococcus aureus & 35 & - & - & - & - & - & - & $32 / 35(91.4)$ \\
\hline $\begin{array}{l}\text { Coagulase-negative } \\
\text { Staphylococcus }\end{array}$ & 32 & - & - & - & - & - & - & $13 / 28(46.4)$ \\
\hline Streptococcus species & 14 & - & - & - & - & - & - & - \\
\hline Enterococcus species* & 6 & - & - & - & - & - & - & - \\
\hline Others & 8 & - & - & $0 / 1$ & $0 / 1$ & $1 / 1(100)$ & $1 / 2(50.0)$ & - \\
\hline Total & 213 & 96/101 (95.0) & 88/94 (93.6) & $86 / 95(90.5)$ & $88 / 102(86.3)$ & $\begin{array}{r}94 / 100 \\
(94.0)\end{array}$ & $\begin{array}{l}80 / 87 \\
\quad(91.9)\end{array}$ & $45 / 63(71.4)$ \\
\hline \multicolumn{9}{|l|}{ ESBL-GNB } \\
\hline Escherichia coli & 8 & $5 / 8(62.5)$ & - & $1 / 8(12.5)$ & $5 / 8(62.5)$ & $8 / 8(100)$ & $8 / 8(100)$ & - \\
\hline Enterobacter cloacae & 4 & $1 / 4(25.0)$ & - & $0 / 4$ & $1 / 4(25.0)$ & $4 / 4(100)$ & $4 / 4(100)$ & - \\
\hline Klebsiella pneumoniae & 3 & $2 / 3(66.6)$ & - & $0 / 3$ & $2 / 3(66.6)$ & $3 / 3(100)$ & $3 / 3(100)$ & - \\
\hline Total & 15 & $8 / 15(53.3)$ & - & $1 / 15(6.7)$ & $8 / 15(53.3)$ & $15 / 15(100)$ & $15 / 15(100)$ & - \\
\hline
\end{tabular}

Note. $E S B L-G N B$ extended-spectrum beta-lactamase-producing Gram-negative bacilli

*No glycopeptide-resistant Enterococcus was isolated 
month study [22]. The exogenous source of multidrugresistant GNB has been examined in the study of Harris et al. [23]. From 1806 previously non-colonized patients, the authors reported 27 patients with ESBL-producing Klebsiella pneumonia acquisition among whom there were 14 patients (52\%) with an isolate similar by molecular typing to an isolate from another patient with an overlapping length of stay in the hospital. The authors suggest that patient-to-patient transmission is an important and underappreciated cause of ESBLproducing Klebsiella pneumonia infection and colonization [23]. In contrast, Tschudin et al. reported that only $1.5 \%$ of acquired colonization was due to patient-to-patient transmission [24]. An environmental contamination as a reservoir for ESBL-GNB colonization has recently been emphasized for Klebsiella pneumoniae [25].

We observed that admission to ICU 1 was protective for ESBL-GNB acquisition. A major difference between ICU 1 and ICUs 2 and 3 was the use of MSD in intubated patients. The benefit of selective decontamination regimens on acquired colonization with multidrug-resistant Gram-negative bacilli has been shown in France [26] as in other European countries [27]. However, selective digestive decontamination does not prevent patient-topatient cross-transmission.

Recent recommendations support a large panel of antibiotics from ceftriaxone to carbapenems in patients with ICUacquired pneumonia [28]. However, antimicrobial use should be based on local antimicrobial susceptibility surveillance data. Taking into account the high negative predictive value of ESBL-GNB colonization for the prediction of ESBL-GNB AI and high 3rd-/4th-generation susceptibility rate, we suggest that non-carbapenem $\beta$-lactams could be safely used in noncolonized patients with AIs in ICUs with low ESBL-GNB prevalence rate. In ESBL-GNB colonized patients, because one-third of AIs were caused by ESBL-GNB and all isolates were susceptible to amikacin, we propose that amikacin will be added to a beta-lactam agent.

There were several limitations to our study. First, due to the low number of ESBL-GNB AI, other risk factors may not have been identified. Second, antimicrobial therapy of AIs was not recorded and the impact of the use of broadspectrum antimicrobials on the incidence of ESBL-GNB AIs could not be assessed. Third, due to the intermittent character of ESBL-GNB screening, transient colonization could have been missed.

In conclusion, in ICUs with low prevalence rate of ESBL-GNB, few ESBL-GNB AIs were reported and prior or simultaneous ESBL-GNB colonization was a major risk factor for infection. In order to treat a suspected pneumonia or BSI acquired in the ICU, our data suggests that carbapenems could be avoided in non-colonized patients and amikacin combination could be used in patients colonized with ESBL-GNB.
Acknowledgments The authors thank Dave Mavrovic for his help in the English writing.

\section{Compliance with ethical standards}

Conflict of interest The authors declare that they have no conflict of interest.

Ethical approval The local ethic committee ("Comité d'éthique du CHU de Rennes") approved the protocol (no. 18.56).

Informed consent This observational retrospective study respects the French reference method MR003. Patients were informed of the study and non-opposition was needed. By the French law, there is no need for patient's written approval.

\section{References}

1. Prowle JR, Echeverri JE, Ligabo EV, Sherry N, Taori GC, Crozier $\mathrm{TM}$ et al (2011) Acquired bloodstream infection in the intensive care unit: incidence and attributable mortality. Crit Care 15(2):R100

2. Rosenthal VD, Bijie H, Maki DG, Mehta Y, Apisarnthanarak A, Medeiros EA et al (2012) International Nosocomial Infection Control Consortium (INICC) report, data summary of 36 countries, for 2004-2009. Am J Infect Control 40(5):396-407

3. Melsen WG, Rovers MM, Groenwold RH, Bergmans DC, Camus C, Bauer TT et al (2013) Attributable mortality of ventilatorassociated pneumonia: a meta-analysis of individual patient data from randomised prevention studies. Lancet Infect Dis 13(8):665671

4. Barbier F, Pommier C, Essaied W, Garrouste-Orgeas M, Schwebel C, Ruckly S et al (2016) Colonization and infection with extendedspectrum $\beta$-lactamase-producing Enterobacteriaceae in ICU patients: what impact on outcomes and carbapenem exposure? J Antimicrob Chemother 71(4):1088-1097

5. Goulenok T, Ferroni A, Bille E, Lécuyer H, Join-Lambert O, Descamps P et al (2013) Risk factors for developing ESBL E. coli: can clinicians predict infection in patients with prior colonization? J Hosp Infect 84(4):294-299

6. Tumbarello M, Spanu T, Sanguinetti M, Citton R, Montuori E, Leone $\mathrm{F}$ et al (2006) Bloodstream infections caused by extendedspectrum-lactamase-producing Klebsiella pneumoniae: risk factors, molecular epidemiology, and clinical outcome. Antimicrob Agents Chemother 50(2):498-504

7. Razazi K, Derde LPG, Verachten M, Legrand P, Lesprit P, BrunBuisson C (2017) Frequency, associated factors and outcome of multi-drug-resistant intensive care unit-acquired pneumonia among patients colonized with extended-spectrum $\beta$-lactamase-producing Enterobacteriaceae. Ann Intensive Care 7:61

8. Bradford PA (2001) Extended-spectrum $\beta$-lactamases in the 21st century: characterization, epidemiology, and detection of this important resistance threat. Clin Microbiol Rev 14(4):933

9. Paterson DL, Bonomo RA (2005) Extended-spectrum-lactamases: a clinical update. Clin Microbiol Rev 18(4):657-686

10. Girometti N, Lewis RE, Giannella M, Ambretti S, Bartoletti M, Tedeschi S et al (2014) Klebsiella pneumoniae bloodstream infection: epidemiology and impact of inappropriate empirical therapy. Medicine (Baltimore) 93(17):298-309

11. Tabah A, Koulenti D, Laupland K et al (2012) Characteristics and determinants of outcome of hospital-acquired bloodstream infections in intensive care units: the EUROBACT International Cohort Study. Intensive Care Med 38:1930-1945 
12. Barbier F, Bailly S, Schwebel C, Papazian L, Azoulay É et al (2018) Infection-related ventilator-associated complications in ICU patients colonised with extended-spectrum $\beta$-lactamase-producing Enterobacteriaceae. Intensive Care Med 44(5):616-626

13. Frencken JF, Wittekamp BHJ, Plantinga NL, Spitoni C, van de Groep K, Cremer OL et al (2018) Associations between enteral colonization with Gram-negative bacteria and intensive care unitacquired infections and colonization of the respiratory tract. Clin Infect Dis 66(4):497-503

14. Jalalzaï W, Boutrot M, Guinard J, Guigon A, Bret L, Poisson D-M et al (2018) Cessation of screening for intestinal carriage of extended-spectrum $\beta$-lactamase-producing Enterobacteriaceae in a low-endemicity intensive care unit with universal contact precautions. Clin Microbiol Infect 24(4):429.e7-429.e12

15. Bruyère $\mathrm{R}$, Vigneron $\mathrm{C}$, Bador $\mathrm{J}$, Aho $\mathrm{S}$, Toitot $\mathrm{A}$, Quenot $\mathrm{J}$ et al (2016) Significance of prior digestive colonization with extendedspectrum $\beta$-lactamase-producing Enterobacteriaceae in patients with ventilator-associated pneumonia. Crit Care Med 44:699-706

16. Camus C, Salomon S, Bouchigny C, Gacouin A, Lavoué S, Donnio $\mathrm{P}-\mathrm{Y}$ et al (2014) Short-term decline in all-cause acquired infections with the routine use of a decontamination regimen combining topical polymyxin, tobramycin, and amphotericin B with mupirocin and chlorhexidine in the ICU: a single-center experience*. Crit Care Med 42(5):1121-1130

17. Garner JS, Jarvis WR, Emori TG, Horan TC, Hughes JM (1988) CDC definitions for nosocomial infections, 1988. Am J Infect Control 16(3): 128-140

18. Detsis M, Karanika S, Mylonakis E (2017) ICU acquisition rate, risk factors, and clinical significance of digestive tract colonization with extended-spectrum beta-lactamase-producing Enterobacteriaceae: a systematic review and meta-analysis. Crit Care Med 45:705-714

19. Houard M, Rouzé A, Ledoux G, Six S, Jaillette E, Poissy J et al (2018) Relationship between digestive tract colonization and subsequent ventilator-associated pneumonia related to ESBLproducing Enterobacteriaceae. PLoS One 13(8):e0201688

20. Martins IS, Pessoa-Silva CL, Nouer SA, Pessoa de Araujo EG, Ferreira ALP, Riley LW et al (2006) Endemic extended-spectrum beta-lactamase-producing Klebsiella pneumoniae at an intensive care unit: risk factors for colonization and infection. Microb Drug Resist 12:50-58

21. Troche G, Joly LM, Guibert M, Zazzo JF (2005) Detection and treatment of antibiotic-resistant bacterial carriage in a surgical intensive care unit: a 6-year prospective survey. Infect Control Hosp Epidemiol 26:161-165

22. Prevel R, Boyer A, M'Zali F et al (2019) Extended spectrum betalactamase producing Enterobacterales faecal carriage in a medical intensive care unit: low rates of cross-transmission and infection. Antimicrob Resist Infect Control 8:112

23. Harris A, Perencevich E, Johnson J, Paterson D, Morris J, Strauss S et al (2007) Patient-to-patient transmission is important in extended-spectrum $\beta$-lactamase-producing Klebsiella pneumoniae acquisition. Clin Infect Dis 45:1347-1350

24. Tschudin-Sutter S, Frei R, Dangel M, Stranden A, Widmer AF (2015) Rate of transmission of extended-spectrum betalactamase-producing Enterobacteriaceae without contact isolation. Clin Infect Dis 11:1505-1511

25. Guet-Revillet H, Le Monnier A, Breton N, Descamps P, Lecuyer H, Alaabouche I et al (2012) Environmental contamination with extended-spectrum $\beta$-lactamases: is there any difference between Escherichia coli and Klebsiella spp? Am J Infect Control 40:845848

26. Camus C, Sauvadet E, Tavenard A, Piau C, Uhel F, Bouju P et al (2016) Decline of multidrug-resistant Gram negative infections with the routine use of a multiple decontamination regimen in ICU. J Infect 73(3):200-209

27. Plantinga NL, Wittekamp BHJ, Brun-Buisson C, Bonten MJM, Cooper BS, Coll P et al (2019) The effects of topical antibiotics on eradication and acquisition of third-generation cephalosporin and carbapenem-resistant Gram-negative bacteria in ICU patients; a post hoc analysis from a multicentre cluster-randomized trial. Clin Microbiol Infect

28. Torres A, Niederman MS, Chastre J, Ewig S, Fernandez-Vandellos $\mathrm{P}$, Hanberger $\mathrm{H}$ et al (2017) International ERS/ESICM/ESCMID/ ALAT guidelines for the management of hospital-acquired pneumonia and ventilator-associated pneumonia: guidelines for the management of hospital-acquired pneumonia (HAP)/ventilator-associated pneumonia (VAP) of the European Respiratory Society (ERS), European Society of Intensive Care Medicine (ESICM), European Society of Clinical Microbiology and Infectious Diseases (ESCMID) and Asociación Latinoamericana del Tórax (ALAT). Eur Respir J 50(3):1700582

Publisher's note Springer Nature remains neutral with regard to jurisdictional claims in published maps and institutional affiliations. 